\title{
Complete genome sequence of Pyrobaculum oguniense
}

David L. Bernick', Kevin Karplus ${ }^{1}$, Lauren M. Lui ${ }^{1}$, Joanna K. C. Coker ${ }^{1}$, Julie N. Murphy', Patricia P. Chan', Aaron E. Cozen', Todd M. Lowe ${ }^{1}$

${ }^{1}$ Biomolecular Engineering, University of California., Santa Cruz, California, USA

Corresponding author: Todd M. Lowe (lowe@soe.ucsc.edu)

Keywords: Pyrobaculum oguniense, Pyrobaculum arsenaticum, Crenarchaea, inversion

Pyrobaculum oguniense TE7 is an aerobic hyperthermophilic crenarchaeon isolated from a hot spring in Japan. Here we describe its main chromosome of 2,436,033 bp, with three large-scale inversions and an extra-chromosomal element of 16,887 bp. We have annotated 2,800 protein-coding genes and 145 RNA genes in this genome, including nine H/ACA-like small RNA, 83 predicted C/D box small RNA, and 47 transfer RNA genes. Comparative analyses with the closest known relative, the anaerobe Pyrobaculum arsenaticum from Italy, reveals unexpectedly high synteny and nucleotide identity between these two geographically distant species. Deep sequencing of a mixture of genomic DNA from multiple cells has illuminated some of the genome dynamics potentially shared with other species in this genus.

\section{Introduction}

Pyrobaculum oguniense TE7T (=DSMZ $13380=J C M 10595)$ was originally isolated from the Tsuetate hot spring in Oguni-cho, Kumamoto Prefecture, Japan [1], and subsequently found to grow heterotrophically at an optimal temperature near $94^{\circ} \mathrm{C}, \mathrm{pH} 7.0$ (at $25^{\circ} \mathrm{C}$ ), and in the presence or absence of oxygen. Under anaerobic conditions, it can utilize sulfur-containing compounds (sulfur, thiosulfate, L-cystine and oxidized glutathione) but not nitrate or nitrite as terminal electron acceptors.

Initial 16S ribosomal DNA sequence analysis [1] placed Pyrobaculum oguniense TE7T in the Pyrobaculum clade and closest to P. aerophilum and Thermoproteus neutrophilus (recently renamed to Pyrobaculum neutrophilum [2]). DNA hybridization studies were conducted with $P$. aerophilum IM2, $P$. islandicum GEO3, $P$. organotrophum $\mathrm{H} 10$ and $T$. neutrophilus (P. neutrophilum) V24Sta, showing little genomic similarity to those species. $P$. arsenaticum $\mathrm{PZ6}^{\mathrm{T}}$ [3] , P. sp. 1860 [4] and P. calidifontis VA1 [5] were not available at that time.

The genus Pyrobaculum is known for its range of respiratory capabilities [6]. Three of the currently known members of the genus can respire oxygen; $P$. aerophilum is a facultative micro-aerobe, while $P$. calidifontis and $P$. oguniense can utilize atmospheric oxygen. P. aerophilum [7], P. calidifontis, and four other metabolically unique Pyrobaculum species have been fully sequenced; together with $P$. oguniense, we sought to further broaden the understanding of this important hyperthermophilic group. Pairwise whole-genome alignments of previously sequenced Pyrobaculum species reveal many structural rearrangements. With the availability of highthroughput sequencing, we were able to further explore rearrangements that occur between species, and our use of a not-quite-clonal population allowed exploration of rearrangements within a single species.

\section{Classification and features}

Figure 1 and Table 1 summarize the phylogenetic position and characteristics of Pyrobaculum oguniense TE7 relative to other members of the Pyrobaculum genus, respectively.

\section{Genome sequencing information} Genome project history

Table 2 presents the project information and its association with MIGS version 2.0 compliance [23].

\section{Growth conditions and DNA isolation}

The initial culture was obtained in 2003 from the Leibniz Institute-German Collection of Microorganisms and Cell Cultures (DSMZ), and grown anaerobically in stoppered, $150 \mathrm{ml}$ glass culture bottles at $90^{\circ} \mathrm{C}$. This culture was stored at $4^{\circ} \mathrm{C}$ for an extended period (six years) before being sampled for this study. 


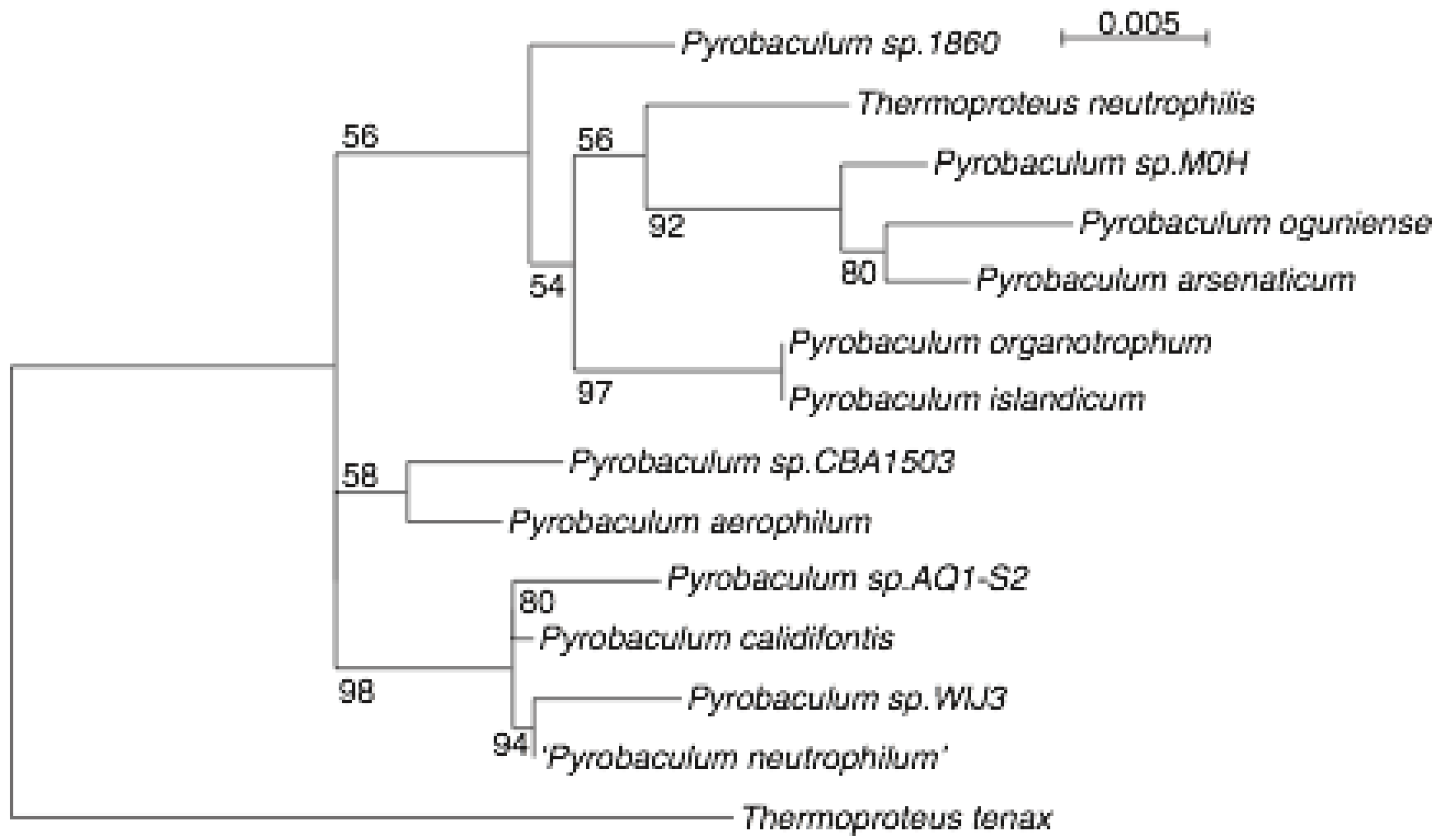

Figure 1. Phylogenetic tree of the known Pyrobaculum species based on $16 \mathrm{~S}$ ribosomal RNA sequence. Accession numbers and associated culture collection identifiers (when available) for $16 \mathrm{~S}$ ribosomal RNA genes are: Pyrobaculum aerophilum (NC_003364.1, DSM 7523); P. calidifontis (NC_009073.1, DSM 21063); P. islandicum (NC_008701.1, DSM 4184); P. arsenaticum (NC_009376.1, DSM 13514); P. oguniense (CP003316, DSM 13380); Pyrobaculum neutrophilum V24Sta / Thermoproteus neutrophilus (NC_010525.1); P.sp. 1860 (CP003098.1); P. organotrophum (AB304846.1, DSM 4185); P. sp.CBA1503 (HM594679.1); P. sp. MOH (AB302407.1); P. sp. AQ1.S2 (DQ778007.1); P. sp. WIJ3 (AJ277125.1). Sequences were aligned using MAFFT v.6 [8], followed by manual curation [9] to remove $16 \mathrm{~S}$ ribosomal introns and all terminal gap columns caused by missing sequence. The maximum likelihood tree was constructed using Tree-Puzzle v. 5.2 [10] using exact parameter estimates, 10,000 quartets and 1000 puzzling steps. Thermoproteus tenax Kra1 (NC_016070.1, DSM 2078) was included as an outgroup. Numbered branches show bootstrap percentages and branch lengths depict nucleotide mutation rate (see scale bar upper right).

A set of ten-fold dilutions of an actively growing culture $\left(\sim 10^{8}\right.$ cells $\left./ \mathrm{ml}\right)$ was carried out and growth was monitored over a five-day period. All cultures were grown at $90^{\circ} \mathrm{C}$ without shaking in 200ml modified DSM 390 medium, using $1 \mathrm{~g}$ tryptone, $1 \mathrm{~g}$ yeast extract, $\mathrm{pH} 7$, supplemented with $10 \mathrm{mM} \mathrm{Na} \mathrm{N}_{2} \mathrm{O}_{3}$ in $1 \mathrm{~L}$ flasks under a headspace of nitrogen. At day four of growth, a new $400 \mathrm{ml}$ aerobic culture was inoculated with $20 \mathrm{ml}$ from the penultimate member of the dilution series $\left(10^{-8}\right)$ and shaken at $100 \mathrm{rpm}$, supplemented with $10 \mathrm{mM} \mathrm{Na}_{2} \mathrm{~S}_{2} \mathrm{O}_{3}$, and subsequently was used for sequencing. We note that at day five, turbid growth was seen in the final member of the dilution series $\left(10^{-9}\right.$ initial dilution). This implies that the initial $10^{-8}$ inoculum used for sequencing likely included more than 10 cells.

Cell pellets were obtained from the $400 \mathrm{ml}$ aerobic culture, frozen at $-80^{\circ} \mathrm{C}$ and suspended in $15 \mathrm{ml}$ SNET II lysis buffer $(20 \mathrm{mM}$ Tris-Cl $\mathrm{pH} 8,5 \mathrm{mM}$ EDTA, 400mM NaCl, 1\% SDS) supplemented with $0.5 \mathrm{mg} / \mathrm{ml}$ Proteinase $\mathrm{K}$ and incubated at $55^{\circ} \mathrm{C}$ for four hours. DNA was extracted from this digest using an equal volume of Tris-buffered (pH 8) PCI (Phenol:Chloroform:Isoamyl-OH (25:24:1)). Following pha se-separation $\left(3220 \mathrm{~g}, 10 \mathrm{~min}\right.$. at $4^{\circ} \mathrm{C}$ ), the resulting aqueous phase was treated with RNase A $(25 \mu \mathrm{g} / \mathrm{ml})$ for 30 minutes at $37^{\circ} \mathrm{C}$. This reaction was PCI-extracted a second time, followed by $\mathrm{CHCl}_{3}$ extraction of the resulting aqueous phase and a final phase separation as before. 
Bernick et al.

Table 1. Classification and general features of Pyrobaculum oguniense according to the MIGS recommendations [11].

\begin{tabular}{|c|c|c|c|}
\hline MIGS ID & Property & Term & Evidence code \\
\hline & \multirow{8}{*}{ Current classification } & Domain Archaea & TAS [12] \\
\hline & & Phylum Crenarchaeota & TAS [13] \\
\hline & & Class Thermoprotei & TAS $[14,15]$ \\
\hline & & Order Thermoproteales & TAS [16-19] \\
\hline & & Family Thermoproteaceae & TAS [16-18] \\
\hline & & Genus Pyrobaculum & TAS $[20,21]$ \\
\hline & & Species Pyrobaculum oguniense & TAS $[1$ \\
\hline & & Type strain TE7 & \\
\hline & Cell shape & rods $0.6-1 \mu \mathrm{m} \times 2-10 \mu \mathrm{m}$ & TAS [1] \\
\hline & Sporulation & no & \\
\hline & Temperature range & $70-97^{\circ} \mathrm{C}$ & \\
\hline & Optimum temperature & $90-94^{\circ} \mathrm{C}$ & \\
\hline & Carbon source & $\begin{array}{l}\text { heterotroph } 1 \mathrm{~g} / \mathrm{L} \text { yeast extract or } 0.5 \mathrm{~g} / \mathrm{L} \text { yeast extract } \\
\text { with } 0.5 \mathrm{~g} / \mathrm{L} \text { tryptone) }\end{array}$ & TAS [1] \\
\hline & Energy source & (see carbon source) & TAS [1] \\
\hline & Terminal electron acceptor & $\mathrm{O}_{2}$, sulfur compounds, no growth on $\mathrm{NO}_{3}$ or $\mathrm{NO}_{2}$ & TAS [1] \\
\hline MIGS-6 & Habitat & hot-spring & TAS [1] \\
\hline MIGS-6.3 & Salinity & $0-1.5 \%(\mathrm{w} / \mathrm{v}) ; 0 \%$ optimal & TAS [1] \\
\hline MIGS-22 & Oxygen & facultative aerobe & TAS [1] \\
\hline MIGS-15 & Biotic relationship & free-living & NAS \\
\hline MIGS-14 & Pathogenicity & none & NAS \\
\hline MIGS-4 & Geographic location & $\begin{array}{l}\text { Tsuetate hot spring, Oguni-cho, Kumamoto prefecture, } \\
\text { Japan }\end{array}$ & TAS [1] \\
\hline MIGS-5 & Sample collection time & June 1997 & NAS \\
\hline MIGS-4.1 & Latitude & 33.186 & NAS \\
\hline MIGS-4.2 & Longitude & 131.031 & NAS \\
\hline MIGS-4.3 & Depth & hot-spring sediment / fluid & NAS \\
\hline MIGS-4.4 & Altitude & $300 \mathrm{~m}$ & NAS \\
\hline
\end{tabular}

Evidence codes - TAS: Traceable Author Statement; NAS: Non-traceable Author Statement. These evidence codes are from the Gene Ontology project [22].

Table 2. Project information

\begin{tabular}{lll}
\hline MIGS ID & Property & Term \\
\hline MIGS-31 & Finishing quality & Finished \\
MIGS-28 & Libraries used & Roche 454 Titanium library, SOLiD 2×25 Mate-pair (1k-3.5k insert) \\
MIGS-29 & Sequencing platforms & 454 GS FLX Titanium, ABI SOLiD \\
MIGS-31.2 & Fold coverage & $59 \times 454,500 \times$ SOLiD \\
MIGS-30 & Assemblers & Newbler 2.0.01.14, Custom \\
MIGS-32 & Gene calling method & Prodigal, tRNAScan-SE \\
& Genome Database release & Genbank \\
& Genbank ID & 379005763 \\
& Genbank Date of Release & 379002962 \\
& GOLD ID & Gc02118 \\
& Project relevance & Biotechnology \\
\hline
\end{tabular}


DNA was precipitated in an equal volume of isopropyl alcohol at $-20^{\circ} \mathrm{C}$ overnight, followed by centrifugation $\left(3,220 \mathrm{~g}, 15 \mathrm{~min}\right.$. at $\left.4^{\circ} \mathrm{C}\right)$. The resulting pellet was washed in $70 \% \mathrm{EtOH}$, pelleted (3220g, $30 \mathrm{~min}$. at $4^{\circ} \mathrm{C}$ ) and aspirated to remove the supernatant. The final DNA pellet was suspended in $1 \mathrm{ml}$ TE $(50 \mathrm{mM}$ Tris-Cl $\mathrm{pH} 8,1 \mathrm{mM}$ EDTA) overnight at room temperature, yielding a final DNA concentration of $0.77 \mu \mathrm{g} / \mu \mathrm{l}$.

\section{Genome sequencing and assembly}

Sequencing was performed by the UCSC genome sequencing center using both Roche/454 GS/FLX Titanium pyrosequencing and the ABI SOLiD system (mate-pair). Pyrosequencing reads were assembled with 59X coverage exceeding Q40 over $99.95 \%(2,449,310$ bases $)$ of the genome, producing 20 contigs at an N50 of 467,815 bp. This assembly included 24 Sanger reads generated by primer-walking across four of the five encoded CRISPR repeat regions. The resulting maximal base-error rate $(<Q 40)$ is 25 in 50,000 .

Contigs were assembled to a single scaffold using the mate-pair library generated for use on the ABI SOLiD sequencer. The library was produced with an insert size range of 1000-3,500 bp, and final sequencing yielded $30,631,205$ read pairs of $25 \mathrm{bp}$ read length. Those read-pairs were mapped to the 20 pyrosequencing-derived contigs to produce a From:: To table of uniquely mapping read-pairs; read-pair counts were accumulated for each of the $20 \times 20$ contig-pair assignments in each of the three possible relative contig orientations (same, converging or diverging). The scaffold closed easily with these data and yielded a single main chromosome with three major inversions and an extrachromosomal element.

\section{Genome annotation}

Gene prediction and annotation was prepared using the IMG/ER service of the Joint Genome Institute [24], where protein coding genes were identified using Prodigal [25]. RNase P RNA [26], SRP RNA and ribosomal RNA(5S, 16S, 23S) were identified by homology to the currently described Pyrobaculum members using the UCSC Archaeal Genome Browser (archaea.ucsc.edu) [27]. Annotation of transfer RNA (tRNA) genes was established using tRNAscan-SE [28], supplemented with manual curation of noncanonical introns. C/D box sRNA genes were identified computationally using Snoscan [29] with extensions supported by transcriptional sequencing [30]. H/ACA-like sRNA genes were identified using transcriptionally-supported homology modeling of experimentally validated sRNA transcripts [31]. CRISPR repeats were identified using CRT [32] or CRISPR-finder [33], with strandedness established by transcriptional sequencing.

\section{Genome properties}

The properties and overall statistics of the genome are summarized in Table 3, Table 4, Table 5, Table 6 , and Table 7 . The single main chromosome (55.08\% GC content) has a total size of 2,436,033 bp. Ultra-deep mate-pair sequencing has revealed three regions of the genome that are present in an inverted orientation within a minority of the population (Table 7). The genome also includes an extrachromosomal element of 16, 887 bp (50.58\% GC), that encodes 35 predicted protein-coding genes. Of those genes, seven have an annotated function and the remaining 28 genes are annotated as hypothetical proteins. Of the seven annotated genes, three are coded with viral functions [35].

The majority of the $P$. oguniense genome is structurally syntenic to the genome of $P$. arsenaticum, and genes found in both species show an average of approximately $97 \%$ nucleotide identity. The $P$. oguniense genome is approximately $15 \%$ larger than $P$. arsenaticum, with the former encoding 536 more (2835 - 2299) open reading frames (ORFs) predicted to be genes. Vast stretches of sequence space are syntenic between the two species (Figure 2 , regions in blue), broken by relatively few regions that appear to arise from either gene loss in $P$. arsenaticum or genomic expansion in P. oguniense, possibly a result of the numerous paREP elements present in these genomes (Figure 2). These repetitive regions are difficult to assemble, and some are putative transposons (PaREP2b, for example).

We can identify specific genes and gene clusters that are present in $P$. oguniense but are missing in $P$. arsenaticum. Notably, the cobalamin synthetic cluster and two thiamine synthetic genes (ThiW and ThiC) are absent in $P$. arsenaticum. The terminal cytochrome cluster associated with aerobic respiration [36] is also absent in P. arsenaticum as expected from an obligate anaerobe. Among the 16 largest deletions in $P$. arsenaticum (relative to $P$. oguniense), four are associated with paREP2 genes, six with paREP1/8, and one with paREP6 (Table 5). 


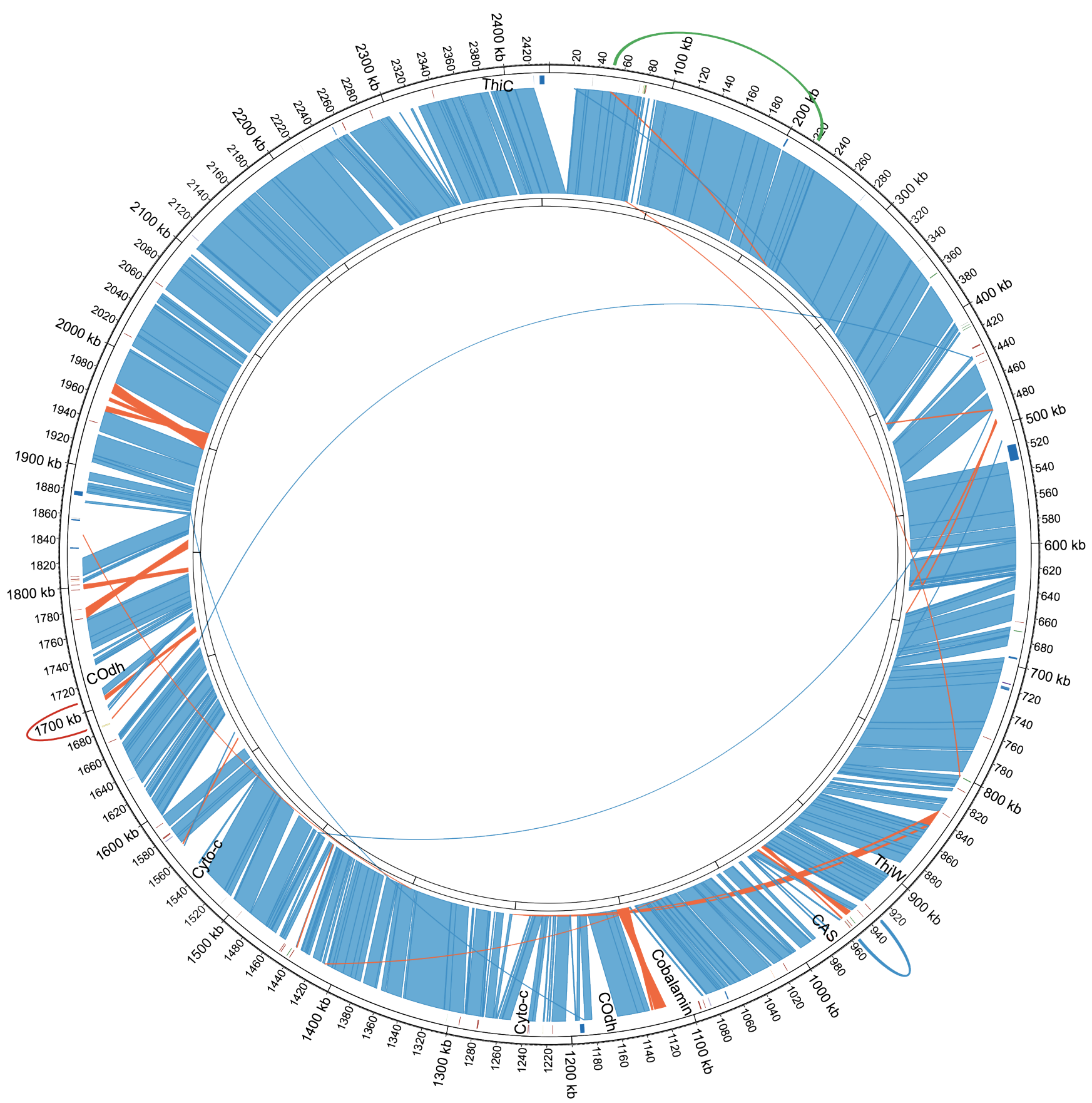

Figure 2. Genomic alignment of $P$. oguniense with $P$. arsenaticum. Outer ring: $P$. oguniense (+ strand); Inner ring: $P$. arsenaticum (- strand). Inter-species alignment blocks shown in light blue and gold (inverted orientation). Intraspecies $P$. oguniense genomic inversions shown as arcs of different colors along outer ring: C8 inversion (red); Glutamate Dehydrogenase (GluDH) inversion (green); RAMP/paREP inversion (blue). Positions of paREP elements shown as ticks inside outer ring: paREP1 (red); paREP2b (blue); paREP7 (green). Positions of selected genes which are present in $P$. oguniense and missing in $P$. arsenaticum are shown in text inside outer ring: thiamine biosynthesis genes (ThiW and ThiC); CRISPR Cassette(CAS); cobalamin cluster; CO dehydrogenase(COdh); and the aerobic cytochrome clusters(Cyto-c). Aligned regions smaller than 500 nucleotides have been removed for clarity. 
Table 3. Nucleotide content and gene count levels of the main chromosome ${ }^{a}$

\begin{tabular}{lrr}
\hline Attribute & Value & \% of total \\
\hline Genome size (bp) & $2,436,033$ & 100 \\
DNA Coding region (bp) & $2,164,251$ & 88.84 \\
DNA G+C content (bp) & $1,341,816$ & 55.08 \\
Total genes & 2,980 & 100 \\
RNA genes & 145 & 4.74 \\
rRNA operons & 1 & \\
Protein-coding genes & 2,800 & 93.96 \\
Genes in paralog clusters & 1,214 & 40.74 \\
Genes assigned to COGs & 1,797 & 60.30 \\
Genes assigned PFAM domains & 1,719 & 57.68 \\
Genes with signal peptides & 794 & 26.64 \\
Genes with transmembrane helices & 646 & 21.68 \\
CRISPR arrays & 5 & $\%$ of total \\
\hline
\end{tabular}

${ }^{a}$ The ECE $(16,887 \mathrm{bp})$ contains 35 genes, has a $50.58 \% \mathrm{G}+\mathrm{C}$ content, and is excluded from this table. Total gene count includes 35 pseudogenes.

Table 4. Number of genes associated with the 25 general COG functional categories

\begin{tabular}{crrl}
\hline Code & Value & \%age $^{\text {a }}$ & Description \\
\hline J & 163 & 8.53 & Translation \\
A & 5 & 0.26 & RNA processing and modification \\
K & 112 & 5.86 & Transcription \\
L & 100 & 5.23 & Replication, recombination and repair \\
B & 4 & 0.21 & Chromatin structure and dynamics \\
D & 22 & 1.15 & Cell cycle control, mitosis and meiosis \\
Y & NA & & Nuclear structure \\
V & 15 & 0.78 & Defense mechanisms \\
T & 45 & 2.35 & Signal transduction mechanisms \\
M & 47 & 2.46 & Cell wall/membrane biogenesis \\
N & 4 & 0.21 & Cell motility \\
Z & 1 & 0.05 & Cytoskeleton \\
W & NA & & Extracellular structures \\
U & 22 & 1.15 & Intracellular trafficking and secretion \\
O & 87 & 4.55 & Post-translational modification, protein turnover, chaperones \\
C & 182 & 9.52 & Energy production and conversion \\
G & 82 & 4.29 & Carbohydrate transport and metabolism \\
E & 159 & 8.32 & Amino acid transport and metabolism \\
F & 58 & 3.04 & Nucleotide transport and metabolism \\
H & 115 & 6.02 & Coenzyme transport and metabolism \\
I & 60 & 3.14 & Lipid transport and metabolism \\
P & 83 & 4.34 & Inorganic ion transport and metabolism \\
Q & 26 & 1.36 & Secondary metabolites biosynthesis, transport and catabolism \\
R & 323 & 16.90 & General function prediction only \\
S & 196 & 10.26 & Function unknown \\
- & 1,144 & & Not in COGs \\
\hline & & &
\end{tabular}

aThe total is based on the 1,911 COG assignments made across 1,701 protein-coding genes with at least one COG assignment. The Not in COGs category is made up of 1,099 hypothetical protein coding genes and 145 RNA genes. The 35 genes in the ECE are excluded from this analysis. 
Table 5. Sixteen largest regions present in Pyrobaculum oguniense and absent in P. arsenaticum.

\begin{tabular}{|c|c|c|}
\hline Region coordinates $(\mathbf{k b})$ & PaRep type & Gene cluster \\
\hline $2,420-0,020$ & paREP2 & \\
\hline $420-440$ & six with paREP1 or paREP1/8 & \\
\hline $485-530$ & paREP2 & \\
\hline $682-695$ & paREP2 & \\
\hline $887-900$ & & ThiW \\
\hline $955-985$ & paREP1/8 & CRISPR cassette \\
\hline $1,090-1,120$ & paREP1 & Cobalamin biosynthesis cassette \\
\hline $1,160-1,180$ & & CO dehydrogenase \\
\hline $1,235-1,250$ & paREP1/8 & \\
\hline $1,440-1,460$ & paREP1/8 & \\
\hline $1,540-1,565$ & & aerobic terminal cytochromes \\
\hline $1,672-1,690$ & paREP6 & \\
\hline $1,715-1,735$ & & CO dehydrogenase \\
\hline $1,780-1,795$ & paREP1 & \\
\hline $1,825-1,870$ & paREP2 & \\
\hline $2,300-2,385$ & & ThiC \\
\hline
\end{tabular}

Table 6. Summary of genome: one chromosome and one extra-chromosomal element

\begin{tabular}{lccc}
\hline Label & Size (bp) & Topology & INSDC identifier \\
\hline & & & \\
Chromosome (Chr) & $2,436,033$ & circular & NC_016885.1 \\
Extra-chromosomal Element (ECE) & 16,887 & circular & NC_016886.1 \\
\hline
\end{tabular}

Table 7. Genomic inversions present within the sampled population

\begin{tabular}{lrrrr}
\hline Inversion name & Start & End & Length & Frequency \\
& 50,930 & 223,540 & 172,611 & 0.17 \\
GluDH & 932,090 & 955,719 & 23,630 & 0.18 \\
RAMP/paREP & & & & \\
C8 & $1,686,376$ & $1,708,299$ & 21,924 & 0.35 \\
\hline
\end{tabular}

aMinority inversion frequency established as described previously [34]. 


\section{Conclusion}

Genomic sequencing and assembly of Pyrobaculum oguniense has yielded a complete genome and an extra-chromosomal element. The main chromosome is largely syntenic to Pyrobaculum arsenaticum and contains a number of gene clusters that are absent in that species. This is of particular interest considering that these species were isolated on opposite sides of the Eurasian continent; $P$. oguniense was isolated in Japan, while $P$. arsenaticum was isolated in an arsenic-rich anaerobic pool in Italy.

The synteny that has been retained between the genomes of $P$. oguniense and $P$. arsenaticum allows a close examination of gene gain or loss events in the genetic history of these two species. $P$. arsenaticum is missing the gene clusters that support cobalamin and thiamine synthesis, and it is missing the aerobic cytochrome cluster. Given that $P$. oguniense and the next closest member in the clade, $P$. aerophilum, have both retained these capabilities; the most parsimonious explanation is gene loss in $P$. arsenaticum. Because these genes are located at disparate positions in the $P$. oguniense genome, it would further appear that these losses are the result of multiple events in the evolutionary history of $P$. arsenaticum.

Within this genome, 145 non-coding RNA genes are described. These include a single operon encoding $16 \mathrm{~S}$ and $23 \mathrm{~S}$ ribosomal RNA, the associated 5S rRNA, the 7S signal recognition particle(SRP), and the RNase P RNA. There are 47 annotated

\section{Acknowledgements}

Sequencing was provided by the UCSC Genome Sequencing Center. We would like to thank Nathan Boyd, Eveline Hesson and Nader Pourmand for their expertise and advice in this work. This work was supported by National Science Foundation Grant DBI-0641061

\section{References}

1. Sako Y, Nunoura T, Uchida A. Pyrobaculum oguniense sp. nov., a novel facultatively aerobic and hyperthermophilic archaeon growing at up to 97 degrees C. Int J Syst Evol Microbiol 2001; 51:303-309. PubMed

2. Chan PP, Cozen AE, Lowe TM. Reclassification of Thermoproteus neutrophilus Stetter and Zillig 1989 as Pyrobaculum neutrophilum comb. nov. based on phylogenetic analysis. Int I Syst Evol Microbiol 2012. PubMed http://dx.doi.org/10.1099/ijs.0.043091-0
tRNA genes, plus a single tRNA pseudogene. Also included are 83 predicted C/D box sRNA genes and nine additional H/ACA-like sRNA, each of which has been transcriptionally validated [31]. The non-coding RNA content of the $P$. oguniense genome has become the most extensively annotated among crenarchaeal genomes to date.

The use of a not-quite-clonal cell population for DNA isolation, coupled with ultra-deep sequencing has provided a view of three major inversions that are each present in over $17 \%$ of the sample population. The boundaries of one of these inversions are defined by an inverted repeat encoding a duplication of glutamate dehydrogenase (GluDH). Notably, this duplication appears to be present in each of the currently sequenced Pyrobaculum members, suggesting that those genomes may also host similar inversions. A second inversion has at its termini another inverted duplication, encoding a gene associated with one of the paREP members and a CRISPR-associated gene. It remains unclear if these common structural variants impart a physiological advantage, and if so, how the variation provides utility to its host. Based on our expanded genome diversity observations, we suggest that avoiding the use of a strictly clonal population for sequencing purposes can provide a significant benefit to understanding both the biology of the host and a clearer understanding of the genome dynamics of the species.

(T.L. and D.B.) and the Graduate Research and Education in Adaptive Bio-Technology (GREAT) Training Program sponsored by the University of California Biotechnology Research and Education Program (D.B.).

3. Huber R, Sacher M, Vollmann A, Huber H, Rose D. Respiration of arsenate and selenate by hyperthermophilic archaea. Syst Appl Microbiol 2000; 23:305-314. PubMed http://dx.doi.org/10.1016/S0723-2020(00)80058$\underline{2}$

4. Mardanov AV, Gumerov VM, Slobodkina GB, Beletsky AV, Bonch-Osmolovskaya EA, Ravin $\mathrm{NV}$, Skryabin KG. Complete genome sequence of strain 1860, a crenarchaeon of the genus pyrobaculum able to grow with various electron 
Bernick et al.

acceptors. J Bacteriol 2012; 194:727-728. Pub-

Med http://dx.doi.org/10.1128/JB.06465-11

5. Amo T, Paje ML, Inagaki A, Ezaki S, Atomi H, Imanaka T. Pyrobaculum calidifontis sp. nov., a novel hyperthermophilic archaeon that grows in atmospheric air. Archaea 2002; 1:113-121. PubMed http://dx.doi.org/10.1155/2002/616075

6. Cozen AE, Weirauch MT, Pollard KS, Bernick DL, Stuart JM, Lowe TM. Transcriptional map of respiratory versatility in the hyperthermophilic crenarchaeon Pyrobaculum aerophilum. I

Bacteriol 2009; 191:782-794. PubMed http://dx.doi.org/10.1128/JB.00965-08

7. Fitz-Gibbon ST, Ladner H, Kim UJ, Stetter KO, Simon MI, Miller JH. Genome sequence of the hyperthermophilic crenarchaeon Pyrobaculum aerophilum. Proc Natl Acad Sci USA 2002; 99:984-989. PubMed http://dx.doi.org/10.1073/pnas.241636498

8. Katoh K, Toh H. Recent developments in the MAFFT multiple sequence alignment program. Brief Bioinform 2008; 9:286-298. PubMed http://dx.doi.org/10.1093/bib/bbn013

9. Waterhouse AM, Procter JB, Martin DM, Clamp M, Barton GJ. Jalview Version 2--a multiple sequence alignment editor and analysis workbench. Bioinformatics 2009; 25:1189-1191. PubMed http://dx.doi.org/10.1093/bioinformatics/btp033

10. Strimmer K, von Haeseler A. Quartet Puzzling: A Quartet Maximum-Likelihood Method for Reconstructing Tree Topologies. Mol Biol Evol 1996; 13:964-969.

http://dx.doi.org/10.1093/oxfordjournals.molbev.a $\underline{025664}$

11. Field D, Garrity G, Gray T, Morrison N, Selengut J, Sterk P, Tatusova T, Thomson N, Allen MJ, Angiuoli SV, et al. The minimum information about a genome sequence (MIGS) specification. Nat Biotechnol 2008; 26:541-547. PubMed http://dx.doi.org/10.1038/nbt1360

12. Woese CR, Kandler O, Wheelis ML. Towards a natural system of organisms: proposal for the domains Archaea, Bacteria, and Eucarya. Proc Natl Acad Sci USA 1990; 87:4576-4579. PubMed http://dx.doi.org/10.1073/pnas.87.12.4576

13. Garrity GM, Holt JG. Phylum AI. Crenarchaeota phy. nov. In: Garrity GM, Boone DR, Castenholz RW (eds), Bergey's Manual of Systematic Bacteriology, Second Edition, Volume 1, Springer, New York, 2001, p. 169-210.
14. List Editor. Validation List no. 85. Validation of publication of new names and new combinations previously effectively published outside the IJSEM. Int I Syst Evol Microbiol 2002; 52:685-690. PubMed http://dx.doi.org/10.1099/ijs.0.02358-0

15. Reysenbach AL. Class I. Thermoprotei class. nov. In: Garrity GM, Boone DR, Castenholz RW (eds), Bergey's Manual of Systematic Bacteriology, Second Edition, Volume 1, Springer, New York, 2001, p. 169.

16. Validation of the publication of new names and new combinations previously effectively published outside the IJSB. List No. 8. Int J Syst Bacteriol 1982; 32:266-268. http://dx.doi.org/10.1099/00207713-32-2-266

17. Zillig W, Stetter KO, Schäfer W, Janekovic D, Wunderl S, Holz J, Palm P. Thermoproteales: a novel type of extremely thermoacidophilic anaerobic archaebacteria isolated from Icelandic solfataras. [Orig A]. Zentralbl Bakteriol 1981; C2:205-227.

18. Burggraf $\mathrm{S}$, Huber $\mathrm{H}$, Stetter KO. Reclassification of the crenarchael orders and families in accordance with 16S rRNA sequence data. Int I Syst Bacteriol 1997; 47:657-660. PubMed http://dx.doi.org/10.1099/00207713-47-3-657

19. Judicial Commission of the International Committee on Systematics of Prokaryotes. The nomenclatural types of the orders Acholeplasmatales, Halanaerobiales, Halobacteriales, Methanobacteriales, Methanococcales, Methanomicrobiales, Planctomycetales, Prochlorales, Sulfolobales, Thermococcales, Thermoproteales and Verrucomicrobiales are the genera Acholeplasma, Halanaerobium, Halobacterium, Methanobacterium, Methanococcus, Methanomicrobium, Planctomyces, Prochloron, Sulfolobus, Thermococcus, Thermoproteus and Verrucomicrobium, respectively. Opinion 79. Int J Syst Evol Microbiol 2005; 55:517-518. PubMed http://dx.doi.org/10.1099/ijs.0.63548-0

20. List Editor. Validation of the publication of new names and new combinations previously effectively published outside the IJSB. List No. 25. Int J Syst Bacteriol 1988; 38:220-222. http://dx.doi.org/10.1099/00207713-38-2-220

21. Huber R, Kristjansson JK, Stetter KO. Pyrobaculum gen. nov., a new genus of neutrophilic, rod-shaped archaebacteria from continental solfataras growing optimally at $100 \mathrm{C}$. Arch Microbiol 1987; 149:95-101. http://dx.doi.org/10.1007/BF00425072 
22. Ashburner M, Ball CA, Blake JA, Botstein D, Butler $\mathrm{H}$, Cherry JM, Davis AP, Dolinski K, Dwight SS, Eppig JT, et al. Gene ontology: tool for the unification of biology. The Gene Ontology Consortium. Nat Genet 2000; 25:25-29. PubMed http://dx.doi.org/10.1038/75556

23. Field D, Garrity G, Gray T, Morrison N, Selengut J, Sterk P, Tatusova T, Thomson N, Allen MJ, Angiuoli SV, Ashburner M. The minimum information about a genome sequence (MIGS) specification. Nat Biotechnol 2008; 26:541-547. PubMed http://dx.doi.org/10.1038/nbt1360

24. DOE. Joint Genome Institute. http://img.jgi.doe.gov

25. Hyatt D, Chen GL, Locascio PF, Land ML, Larimer FW, Hauser LJ. Prodigal: prokaryotic gene recognition and translation initiation site identification. BMC Bioinformatics 2010; 11:119. PubMed http://dx.doi.org/10.1186/1471-2105-11-119

26. Lai LB, Chan PP, Cozen AE, Bernick DL, Brown JW, Gopalan V, Lowe TM. Discovery of a minimal form of RNase P in Pyrobaculum. Proc Natl Acad Sci USA 2010; 107:22493-22498. PubMed http://dx.doi.org/10.1073/pnas.1013969107

27. Chan PP, Holmes AD, Smith AM, Tran D, Lowe TM. The UCSC Archaeal Genome Browser: 2012 update. Nucleic Acids Res 2012; 40(Database issue):D646-D652. PubMed http://dx.doi.org/10.1093/nar/gkr990

28. Lowe TM, Eddy SR. tRNAscan-SE: a program for improved detection of transfer RNA genes in genomic sequence. Nucleic Acids Res 1997; 25:955-964. PubMed

29. Lowe TM, Eddy SR. A computational screen for methylation guide snoRNAs in yeast. Science 1999; 283:1168-1171. PubMed http://dx.doi.org/10.1126/science.283.5405.1168

30. Bernick DL, Dennis PP, Lui LM, Lowe TM. Diversity of antisense and other non-coding RNAs in Archaea revealed by comparative small RNA se- quencing in four Pyrobaculum species. Frontiers in Microbiology 2012;3.

http://dx.doi.org/10.3389/fmicb.2012.00231

31. Bernick DL, Dennis PP, Hochsmann M, Lowe TM. Discovery of Pyrobaculum small RNA families with atypical pseudouridine guide RNA features. RNA 2012; 18:402-411. PubMed http://dx.doi.org/10.1261/rna.031385.111

32. Bland C, Ramsey TL, Sabree F, Lowe M, Brown K, Kyrpides NC, Hugenholtz P. CRISPR recognition tool (CRT): a tool for automatic detection of clustered regularly interspaced palindromic repeats. BMC Bioinformatics 2007; 8:209. PubMed http://dx.doi.org/10.1186/1471-2105-8-209

33. Grissa I, Vergnaud G, Pourcel C. CRISPRFinder: a web tool to identify clustered regularly interspaced short palindromic repeats. Nucleic Acids Res 2007;35(Web Server issue):W52-57

34. Bernick DL. Sequential discovery - from small RNA to genomes, an investigation of the hyperthermophilic genus Pyrobaculum. Santa Cruz, California USA: University of California, Santa Cruz; 2010. 120 p.

35. Krupovic M, Bamford DH. Archaeal proviruses TKV4 and MVV extend the PRD1-adenovirus lineage to the phylum Euryarchaeota. Virology 2008; 375:292-300. PubMed http://dx.doi.org/10.1016/j.virol.2008.01.043

36. Nunoura T, Sako Y, Wakagi T, Uchida A. Regulation of the aerobic respiratory chain in the facultatively aerobic and hyperthermophilic archaeon Pyrobaculum oguniense. Microbiology 2003; 149:673-688. PubMed http://dx.doi.org/10.1099/mic.0.26000-0

37. Sako Y, Nunoura T, Uchida A. Pyrobaculum oguniense sp. nov., a novel facultatively aerobic and hyperthermophilic archaeon growing at up to 97 degrees C. Int J Syst Evol Microbiol 2001; 51:303-309. PubMed 